\title{
Journal of Textile Science \& Engineering
}

\section{Impact of Modified Glyoxalic and Co-polymer Acrylic Crosslinkers Effect on the Crystallinity and Mechanical Properties of Finished Cotton}

\section{Nasr Litim*}

Department of Engineering, National University of Monastri, Tunisia

\begin{abstract}
This paper presents the impact of modified glyoxalic (DMDHEU) and co-polymer acrylic crosslinkers effect on the Crystallinity, Crystallite Size and mechanical properties of finished cotton. Using a modern technical analysis is very significant to describe the outside modification of cellulose fiber and the inside of crystalline region. The obtained results make clear the morphology cross-linking aspect after the treatment of resin with the previously cited Crosslinkers. Benchmarking the effect of used Crosslinkers at various finishing conditions (curing temperature, curing time, drying temperature, drying time and crosslinkers concentration) on crystallinity, crystallite size and surface morphology of finished cotton, is the answer of durable press application problems. It inspects the modified glyoxalic crosslinkers upshot more than acrylic crosslinkers on mechanical properties of cotton yarns. It proves that crystallinity index and crystallite size distinction of treated cotton have a way to link with cellulose physical properties, such as the ability to cross-link in amorphous region. The results also describe the effect of two crosslinkers on the fall mechanical properties of treated cotton. They show an important change on retention of breaking strength and elongation, creep and relaxation rate of treated cotton.
\end{abstract}

Keywords: Crosslinkers; Finishing; Crystallinity; Cotton; Mechanical properties

\section{Introduction}

Crosslinkers have the aptitude to enter in crystalline region of cellulose fiber and connect cellulose inter-chains. They also make a network in relation with the curing and drying condition which is a key element in textile development. Crosslinkers are generally small molecules that enclose a number of functional groups. They are able to link with a number of dynamic groups in the polymer such as hydroxyl groups in cellulose. In order to develop the durable press applied on cotton fabric, the advanced application has been to link a covalently crosslinking agent with adjoining cellulose chains inside fibers [1-3]. The family of crosslinkers that are used with cellulose is classified into two categories: self-polymerized polymers as well as crosslink cellulose and cellulose reactants. In the first hypothesis, three-dimensional polymers are created. In the second, the molecules of crosslinking agents are capable of creating a covalent bond at the moment they react with the cellulose hydroxyl groups $(\mathrm{O}-\mathrm{H})$ [4-6]. Dimethyloldihydroxyethyleneurea (DMDHEU) is the frequently used crosslinkers because it offers high-quality durable press properties at low charge and is less detrimental to fabric strength and other properties compared to other crosslink's agents. Generally, for cellulosic fabric, the resin treatment includes different application methods, such as impregnating it with the pre-condensate and consequently it penetrates into the fibers and then cures at temperatures between $130^{\circ} \mathrm{C}$ and $180^{\circ} \mathrm{C}$ in the presence of a catalyst. Therefore, the pre-condensate is changed into insoluble crosslinking agents by polycondensation and around the cellulosic fibers and/or by reacting with the cellulose chain to structure a network form $[1,2,7]$. DMDHEU is a conventional resin that is usually applied in wash-and-wear and durable press treatments. That is why, it has many characteristics to be used in the recent experimentations by means low quantity of free formaldehyde [8]. The reaction of crosslinkage among cellulose and glyoxalic crosslinkers with the existence of acid catalyst is shown in Figure 1a and b.

There are multiple publications on the X-ray diffraction investigating changes in the structure of cotton as a result of chemical treat swelling or mercerized agents and finished products $[9,10]$. There are few references utilizing the X-ray diffraction method to examine the reaction and the change with cotton to a chemical crosslinkers $[8,11,12]$. Researchers investigated the effect of the crosslinking of the cotton fibers bleached by X-ray diffraction. They were looking for the crystalline structure of the cotton fibers after bleaching, crosslinking and a mixture of bleach and crosslink treatment. They stated that the crosslinking of bleached cotton did not alter the crystalline nature of cotton but increased the degree of crystallinity when cross-linked with either DMDHEU or citric acid. The cross-linked formaldehyde was comparatively less crystalline [8]. In addition, Yang et al. studied the relation between the mechanical strength of cotton treated after durable press finishing and the molecular structure of crosslinkers. They used the FTIR spectroscopy to identify the crosslinking mechanism of cellulose and analysis of polymeric materials [13-15].

The aim of this investigation and benchmarking of different cellulosic crosslinkers is to predict the effect of modified glyoxalic and acrylic crosslinkers on the mechanical properties of cotton yarns. After finishing treatment, the structure and organization of cotton cellulose was studied using X-ray diffraction and ATR FT-IR spectroscopy. It is known that cellulose microfibrils in cotton are composed of crystalline and amorphous regions. With the aid of X-ray diffraction XRD, it will be easy to determine the crystallinity values and crystallite size of the treated cotton yarns. Crystallinity index is known to measure the relative amounts of amorphous and crystalline cellulose. The obtained change in the amorphous and crystalline of cellulose fiber is a result of intermolecular and intermolecular hydrogen link [8]. ATR-FTIR

*Corresponding author: Nasr Litim, Department of Engineering, Nationa University of Monastri, Tunisia, Tel: +216-73500244; E-mail: nasr.litim@gmail.com

Received February 08, 2019; Accepted February 20, 2019; Published February 27,2019

Citation: Litim N (2019) Impact of Modified Glyoxalic and Co-polymer Acrylic Crosslinkers Effect on the Crystallinity and Mechanical Properties of Finished Cotton. J Textile Sci Eng 9: 391. doi: 10.4172/2165-8064.1000391

Copyright: () 2019 Litim N. This is an open-access article distributed under the terms of the Creative Commons Attribution License, which permits unrestricted use, distribution, and reproduction in any medium, provided the original author and source are credited. 
Citation: Litim N (2019) Impact of Modified Glyoxalic and Co-polymer Acrylic Crosslinkers Effect on the Crystallinity and Mechanical Properties of Finished Cotton. J Textile Sci Eng 9: 391. doi: 10.4172/2165-8064.1000391

Page 2 of 8
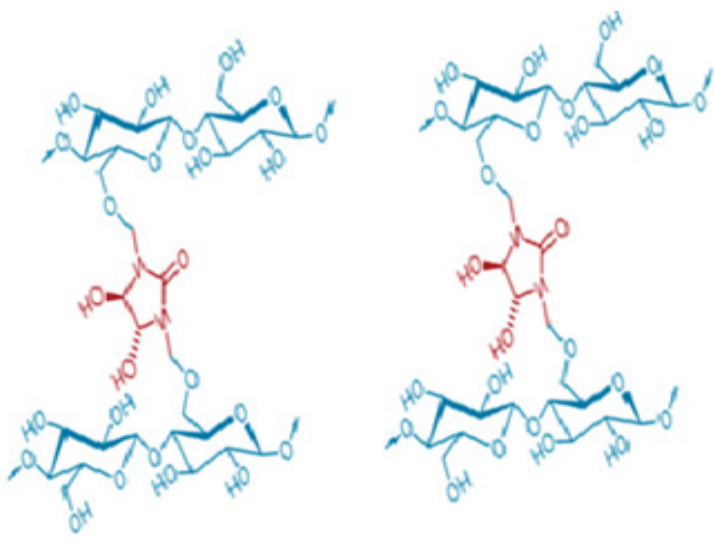

(a)

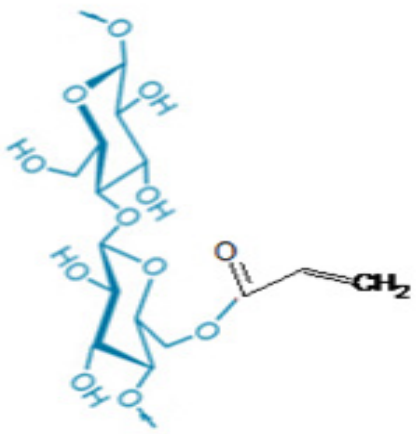

(b)

Figure 1: a) Cross-linking reaction of a cellulose with the modified glyoxalic crosslinkers (DMDHEU) in presence of catalyst, curing temperature is among $140-160^{\circ} \mathrm{C}$, curing time $5(\mathrm{~min})$.

b) Cross-linking reaction of cellulose unit with co-polymer acrylic at $95-140^{\circ} \mathrm{C}$ curing time $5(\mathrm{~min})$ and for $\mathrm{pH}=7$. spectroscopy is a relatively simple and inexpensive method to evaluate the functional chemical groups of finishing crosslinkers [15]. Today, a characterization of X-ray diffraction allows describing the changes of crystallinity values in the treated cotton yarns and understanding the crosslinkers' treatment concept. We found that the change in the internal structure of the cotton is related to a chemical characteristic of crosslinkers and to curing conditions (temperature and time). This change is converted to the physic-chemical properties such as accessibility and reactivity to the catalyst, resin and chemicals additives, breaking strength and elongation of yarns, etc.

\section{Experimental}

The experiment consisted in using a $100(\%)$ cotton yarns $\mathrm{Nm} 14$. It is the most used cotton as warp and weft in the denim woven structure. Two types of finishing crosslinkers are used. Table 1 gives details of used crosslinkers and catalysts.

These crosslinkers are usually used to fix treatments of denim garments, permanent press and wash and wear treatments. The selected crosslinkers are usually used to improve the durable press properties of fabrics. In addition, modified glyoxalic and acrylic crosslinkers can make up ester links with the cellulose chains [16-21] as shown in Figure la and $b$.

For the resin treatment, we used a pad dry cure process. The yarn is impregnated in a bath containing a diluted crosslinkers solution: crosslinkers agent (resin), catalyst (15\%) of crosslinkers weight) and water. Drying is carried out in a ream "Mathis AG-Switzerland", while the curing step is realized in a drying oven. To examine sequentially the comparative effect of crosslinkers on the mechanicals properties of finished cotton yarns. Details of experiments conditions shown in Table 2 .

To identify the crosslinkers characteristics and change on physical (crystallinity) and mechanical properties of treated and untreated cotton yarn, the crosslinkers and finished yarns (samples) were

\begin{tabular}{|c|c|c|c|c|c|c|}
\hline Crosslinkers & $\mathrm{pH}\left(20^{\circ} \mathrm{C}\right)$ & $\begin{array}{l}\text { Viscosity } \\
(\mathrm{cPo}) \\
\left(20^{\circ} \mathrm{C}\right)\end{array}$ & Density & Agent description & Catalysts & Catalyst description \\
\hline $\begin{array}{l}\text { Modified } \\
\text { glyoxalic }\end{array}$ & $3-5,5$ & 184 & 1,3 & $\begin{array}{l}\text { Modified DMDHEU (diethylene glycol } 15-22(\%) \\
\text { and Formaldehyde }<0,1(\%) \text {, and methanol }<0,5 \\
(\%)) \text { crosslinks at } 140\left({ }^{\circ} \mathrm{C}\right)\end{array}$ & MG & Contains Magnesium Chloride $\left(\mathrm{MgCl}_{2}\right)$ \\
\hline Acrylic & $5,5-7,5$ & 107 & 1 & co-polymer self-crosslinked crosslinks at $100\left({ }^{\circ} \mathrm{C}\right)$ & PAZ & $\begin{array}{c}\text { Water dispersion anionic, soluble of the reticulate } \\
\text { agent .It's totally y free of thoxylate alkylphenoles, } \\
\text { plasticizing agents making condensation already } \\
\text { at low temperature. }\end{array}$ \\
\hline
\end{tabular}

Table 1: Basic Properties of crosslinkers.

\begin{tabular}{|c|c|c|c|c|c|c|}
\hline Sample code & Crosslinkers name & $\begin{array}{c}\text { Crosslinkers } \\
\text { concentration }\left(\mathrm{g} \cdot \mathrm{I}^{-1}\right)\end{array}$ & $\begin{array}{l}\text { Dry temperature } \\
\left({ }^{\circ} \mathrm{C}\right) \mathrm{TS}\end{array}$ & Dry time (min) DS & $\begin{array}{l}\text { Curing temperature } \\
\left({ }^{\circ} \mathrm{C}\right) \mathrm{TP}\end{array}$ & Curing time (min) DP \\
\hline YS1 & Modified glyoxalic & 60 & 80 & 1 & 110 & 5 \\
\hline YS2 & Modified glyoxalic & 150 & 80 & 1 & 110 & 5 \\
\hline YS3 & Modified glyoxalic & 60 & 100 & 1 & 110 & 5 \\
\hline YS4 & Modified glyoxalic & 60 & 80 & 5 & 110 & 5 \\
\hline YS5 & Modified glyoxalic & 60 & 80 & 1 & 140 & 5 \\
\hline YS6 & Modified glyoxalic & 60 & 80 & 1 & 110 & 30 \\
\hline TYA1 & Acrylic & 60 & 80 & 1 & 110 & 5 \\
\hline TYA2 & Acrylic & 150 & 80 & 1 & 110 & 5 \\
\hline TYA3 & Acrylic & 60 & 100 & 1 & 110 & 5 \\
\hline TYA4 & Acrylic & 60 & 80 & 5 & 110 & 5 \\
\hline TYA5 & Acrylic & 60 & 80 & 1 & 140 & 5 \\
\hline TYA6 & Acrylic & 60 & 80 & 1 & 110 & 30 \\
\hline
\end{tabular}

Table 2: Details of experiments conditions. 
examined with Scanning Electronic Microscopy analyzer, ATR FT-IR spectroscopy, and $\mathrm{X}$-ray diffraction.

Micrographs of the untreated and processed cotton yarn were taken with a SEM "Hitachi SU 3500-Japan". A scatter coater has been used to pre-conductive gold coating on the surface prior to observing the microstructure. ATR FT-IR Spectroscopy "PerkinElmer-France" used in the investigation of treated yarns. It a cogent tool to discuss the training of inter- and intra-molecular hydrogen bonding in cellulose. The detailed database enables the creation of a strong correlation among the nature of the hydrogen bonds and the physical and mechanical properties of cellulose. It is known that the crystallinity, as a significant parameter of the crystalline polymer, is strictly linked to the physical and mechanical properties of the polymer [16]. To determine the crystallinity at different conditions, the treated samples were discrete on a stump placed in the room of a (D max) shaft Analytical X-Ray diffractometer "X'pert Pro MRD-Netherlands" with a wavelength of $1,54(\AA)$. The generator intensity was $40(\mathrm{kV})$ and generator current was $50(\mathrm{~mA})$. The samples were then scanned using $\left(2 \Theta=5-100^{\circ}\right)$. The rotation speed of clinometers was $8 \% \mathrm{~min}$. The crystallinity index $\mathrm{CI}$ $((\%))$ is defined in the following equation (1):

$$
\mathrm{CI}=100[(\mathrm{I} 002-\mathrm{I} \mathrm{am}) / \mathrm{I} 002]
$$

Where (I 002) presents the crystalline peak of the highest intensity at $2 \Theta$ (between $22^{\circ}$ and $23^{\circ}$ ), and ' $\mathrm{I}$ am' is the lowest intensity at $2 \Theta$ (between $18^{\circ}$ and $19^{\circ}$ ), generally used for cellulose I. [17]. The crystallites sizes were definite with a diffraction model resulted from the (L002) plan of treated cotton yarns. In order to calculate the crystallite size with (L002) plan [18], we used a famous Sherrer's equation (2) as shown below:

$$
\mathrm{L} 002=\mathrm{K} \lambda /(\beta \cos \Theta) \text {. }
$$

Where $\lambda$ is the wavelength of radiation $(1,54 \AA), \Theta$ is the celebrated "Bragg" angle of the diffraction peak in degree, and $\mathrm{K}$ is the constant habitually taken as 0,9 and is the full width at half maximum intensity in radians measured at $2 \Theta$.

The mechanical property of cotton yarn includes; breaking strength, breaking elongation, creep, relaxation rate of treated yarns are studied. They are evaluated with "LLOYD LS5-China" tensile tester according to the standard ISO 2062 (2014). For creep and relaxation test, a loading speed of $100(\mathrm{~mm} / \mathrm{min})$ and keeping the time of $10 \mathrm{~min}$ were used. A creep stress was maintained at $5(\mathrm{~N})$ during 10 (min) with loading speed of $100(\mathrm{~mm} / \mathrm{min})$. All samples were conditioned during 24 hours in a relaxed state $\left(22^{\circ} \mathrm{C}, 60 \% \mathrm{HR}\right)$ according to the standard ISO 13934-1.

\section{Results and Discussion}

\section{Analysis of morphological properties, characterization of crosslinkers and treated cotton with ATR-FTIR spectroscopy}

The treated cotton yarns were examined with SEM and pictures were displayed in Figure 2. Referring to Figure 2, the untreated fibers have an irregular surface with sufficient runnel and spot on the surface. Comparing (a) (b) and (c), it is clear that the yarns and fibers are covered with the crosslinking agent and there is an excess of outstanding crosslinking between neighbouring fibers after the treatment process. It is known that $(-\mathrm{OH})$ molecule in the modified DMDHEU glyoxalic resin reacts with $(-\mathrm{OH})$ molecule of cellulose chains in addition to a chain $[1,2,5]$. Acrylic agent covers most of the fiber and the fiber of spaces seen in Figure 2 that can cause changes in the mechanical properties and crystallinity. This will be discussed later. Acrylic agent appears to be a cover film on the fiber surface and in the gap inter-fiber [21]. These pictures confirm the making of a covering phenomenon that changes the circumferential aspect of yarns. Thereafter, this picture morphology result will clarify the effect on the mechanical properties yarns.

In order to provide a further clarification of the effect of crosslinking agent reaction with a natural fiber, we may begin by studying the functional chemical group. Actually, ATR-FTIR is yet an extra advanced technique to investigate hydrogen link in cellulose. Since 1950, The FTIR has been the best means to examine the full area of hydroxyl group stretching in the ATR-FTIR wave-number of cellulose I (cotton) (Figure 2) [12].

Figure 3 shows the ATR- FTIR spectra of modified glyoxalic and acrylic crosslinkers. It is clear that the detected values of wave-numbers correspond to a chemical group vibration for the studied finishing agent. The modified glyoxalic DMDHEU has a specific wave-number $3352\left(\mathrm{~cm}^{-1}\right)$ that corresponds to the specific O-H group. As for acrylic agent, it has a wave-number $1697 \mathrm{~cm}^{-1}$ that corresponds to specific $\mathrm{C}=\mathrm{O}$ group. Thanks to ATR-FTIR, Qinhuo Fan declared that the acrylic agent has a typical absorption of peak among wave-numbers of 1100 and $1150\left(\mathrm{~cm}^{-1}\right)$ designed for the group of alkyl C-O-C stretching band, in addition to wave-numbers of $1750\left(\mathrm{~cm}^{-1}\right)$ for the group of $\mathrm{C}=\mathrm{O}$ stretching band. He has announced that, when the acrylic polymer structure includes a quantity of vinyl monomers, there will appear a wide peak at wave-numbers of $3020\left(\mathrm{~cm}^{-1}\right)$ and a physically powerful peak at wave-numbers of $1660\left(\mathrm{~cm}^{-1}\right)$ designated for the stretching bands of the groups $\mathrm{C}-\mathrm{H}$ and $\mathrm{C}=\mathrm{C}$ in $\mathrm{CH}=\mathrm{CH}$ composition correspondingly [22].

The wave-numbers corresponding to the chemical group vibration of crosslinkers are presented in Table 3.

The ATR-FTIR spectra of untreated and treated cotton yarns with glyoxalic and acrylic crosslinkers at different finishing conditions and results is shown in Figure 3.

In order to appreciate the effect of two cross-linking agents and the effect of finishing condition on the physicals properties of the crosslinked samples, we extracted the wave number of change peaks from Figure 4 and then presented them in Table 4.

It has long been known that cotton has an important number of $\mathrm{OH}$ groups. The large peak above $3300\left(\mathrm{~cm}^{-1}\right)$ is designated to the $\mathrm{OH}$ group and the low group at $1640\left(\mathrm{~cm}^{-1}\right)$ are owed to hydration.

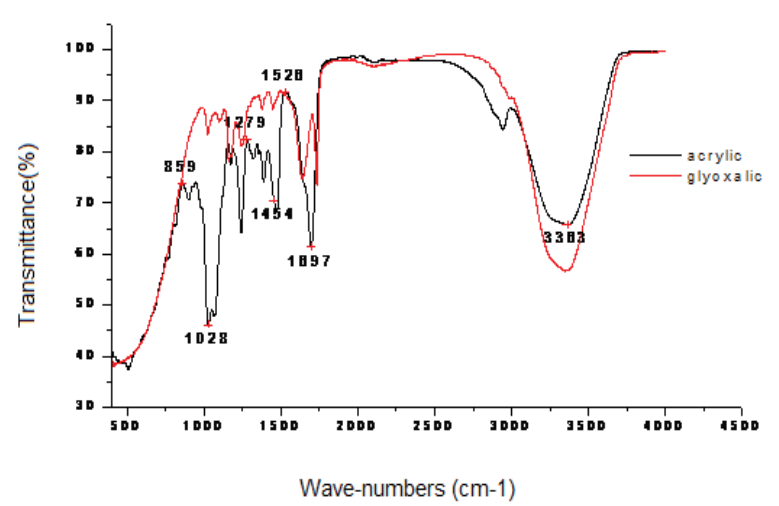

Figure 2: ATR-FTIR spectra of modified glyoxalic and acrylic crosslinkers (wave-number from 400 to $4000\left(\mathrm{~cm}^{-1}\right)$ ). 
Citation: Litim N (2019) Impact of Modified Glyoxalic and Co-polymer Acrylic Crosslinkers Effect on the Crystallinity and Mechanical Properties of Finished Cotton. J Textile Sci Eng 9: 391. doi: 10.4172/2165-8064.1000391

Page 4 of 8

\begin{tabular}{|c|c|c|}
\hline Crosslinkers & wave-number $\mathbf{( c m}^{-1} \mathbf{)}$ & Chemical group vibration \\
\hline \multirow{4}{*}{ Acrylic } & 1028 & $\mathrm{C}-\mathrm{C}$ \\
\cline { 2 - 3 } & 1279 & $\mathrm{C}-\mathrm{O}$ \\
\cline { 2 - 3 } & 1454 & $\mathrm{C}-\mathrm{H}$ \\
\cline { 2 - 3 } & 1526 & $\mathrm{C}=\mathrm{C}$ \\
\hline \multirow{3}{*}{$\begin{array}{c}\text { Modified } \\
\text { glyoxalic } \\
\text { DMDHEU }\end{array}$} & 1697 & $\mathrm{C}=\mathrm{O}$ \\
\cline { 2 - 3 } & 3363 & $\mathrm{O}-\mathrm{H}$ \\
\hline & 1161 & $\mathrm{C}-\mathrm{C}$ \\
\hline & 1415 & $\mathrm{C}-\mathrm{C}$ \\
\hline
\end{tabular}

Table 3: Corresponding wave-numbers to chemical group vibration of two crosslinkers
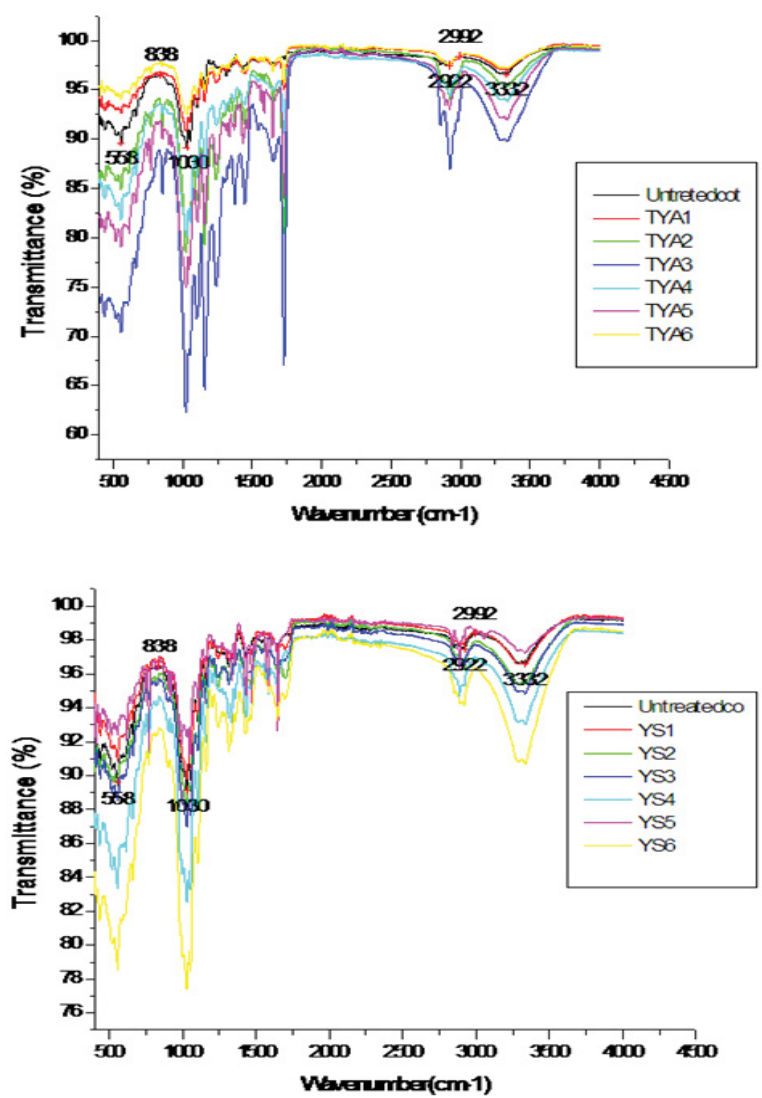

Figure 3: ATR-FTIR spectra of untreated and treated cotton yarns with glyoxalic and acrylic crosslinkers at different finishing conditions (wave number from 400 to $\left.4000\left(\mathrm{~cm}^{-1}\right)\right)$.

After the resin treatment, new peaks occur at $1730\left(\mathrm{~cm}^{-1}\right)$, which can be attributed to $\mathrm{C}-\mathrm{O}$ stretching vibration of groups in the resin. These peaks show that the resin agent has been successfully applied to the surface of cotton. They also have a chemical reaction that was taken to create the ether bonds in $\mathrm{OH}$ group of modified glyoxalic (DMDHEU) with cellulose fiber $[19,20]$.

In fact, many factors can be the origin of change in the wave-number peaks obtained. They have changed a crosslinkers concentration, dry temperature and time, curing temperature and time, seen in Table 2, and the catalyst effect for each type of crosslinkers agent. In our case, the change of the obtained wave-number peaks could not be in relation with a catalyst nature. Yang et al. note that the quantity of the catalyst used in a reaction is related to the reactivity of the reactants and the curing temperature and curing time. Catalyst categories, the quantity of catalyst, or the curing temperature and curing time are the most factors that can be varied to help them and make better their reactivity. It is known that excessive curing temperature and curing time can burn cellulosic fabrics and color them to yellow. A temperature of $180^{\circ} \mathrm{C}$ is usually making use of the curing temperature for formaldehyde-free in durable press [13]. Using ATR-FTIR, the researcher approves of a lot of crosslinking among crosslinkers and fibers after finishing. The cotton treated with modified DMDHEU crosslinkers has better wrinkle recovery angle and decreases in tensile strength values with increasing fabric weight, while softeners are used in textile wet processing to make better fabric handless and mechanical properties [23].

\section{Characterization of treated cotton yarns with X-ray diffraction}

In order to explain the specific effect of used crosslinkers and applied curing and drying conditions on mechanical properties, crystallinity and crystallite size of untreated cotton yarns are treated with glyoxalic and acrylic crosslinkers at different finishing conditions. We summarize the obtained results in Table 5.

Table 5 shows that for all treated yarns, the crystallinity index with acrylic crosslinkers is less than the crystallinity index of untreated cotton. The reaction of modified glyoxalic has an important change in crystallinity index, crystallite size, and mechanical properties. This change is related to the applied crosslinkers characteristics. The crystalline arrangement of the cellulose and availability of $\mathrm{OH}$ groups are restricted to reactivity with reactive agents $[7,9,24]$. Researchers point out that crystallinity index CI for natural cotton is $85,3 \%$. With reference to Table 5, it is clear that the breaking strength values for treated cotton yarns TYA $\mathrm{j}$ (1-6) are higher than the breaking strength of untreated cotton. Meyer and Misch used an X-ray diffraction study and molecular modelling technique in order to invent a construction of the unit cell model of raw cellulose (also known as cellulose I) and their intra- and inter-molecular bonding $[25,26]$. Therefore, to give details of a crystallite size change, it is necessary to distinguish the unit cell model of cellulose.

With reference to Table 5, we notice that modified glyoxalic crosslinkers affect a decrease on crystallinity index maximum $15 \%$ with modified glyoxalic when compared to crystallinity index of untreated cotton. This decrease in crystallinity index approves the decrease in breaking strength between $12 \%$ and $30 \%$ and decrease on breaking elongation between $18 \%$ and $36 \%$ compared to untreated cotton. For acrylic crosslinkers, there is a decrease in crystallinity index by about $10 \%$ maximum when compared to crystallinity index of

\begin{tabular}{|c|c|c|c|c|c|c|c|c|}
\hline & \multicolumn{7}{|c|}{ Wave-number $\mathbf{( c m}^{-1} \mathbf{)}$ of peak } \\
\hline TYA1 & 556 & 837 & 1027 & 1499 & 1726 & 2921 & 3033 & 3337 \\
\hline TYA2 & & 829 & 1022 & 1507 & 1728 & 2921 & 3041 & 3341 \\
\hline TYA3 & & 888 & 1023 & 1506 & 1728 & 2924 & 3033 & 3333 \\
\hline TYA4 & 557 & 836 & 1029 & 1497 & 1729 & 2922 & 3018 & 3337 \\
\hline TYA5 & & 837 & 1024 & 1518 & 1729 & 2920 & 3032 & 3332 \\
\hline TYA6 & 555 & 838 & 1025 & 1385 & 1726 & 2920 & 3033 & 3336 \\
\hline YS1 & 557 & 838 & 1030 & 1384 & 1647 & 2890 & 2922 & 3333 \\
\hline YS2 & 556 & 847 & 1028 & 1458 & 1698 & 2920 & 3016 & 3291 \\
\hline YS3 & 557 & 838 & 1030 & 1510 & 1647 & 2918 & 2990 & 3332 \\
\hline YS4 & 556 & 838 & 1030 & 1334 & 1647 & 2880 & 2991 & 3333 \\
\hline YS5 & 618 & 840 & 1047 & 1435 & 1647 & 2880 & 2956 & 3334 \\
\hline YS6 & 557 & 838 & 1029 & 1315 & 1647 & 2919 & 2992 & 3334 \\
\hline
\end{tabular}

Table 4: Wave-number peaks change of treated samples. 
Citation: Litim N (2019) Impact of Modified Glyoxalic and Co-polymer Acrylic Crosslinkers Effect on the Crystallinity and Mechanical Properties of Finished Cotton. J Textile Sci Eng 9: 391. doi: 10.4172/2165-8064.1000391

Page 5 of 8

\begin{tabular}{|c|c|c|c|c|c|c|}
\hline Yarn code & Crosslinkers & $\begin{array}{l}\text { Crystallinity index } \\
\text { Cl (\%) }\end{array}$ & Crystallite size $(\mathrm{nm})$ & Breaking strength $(\mathrm{N})$ & $\begin{array}{c}\text { Breaking elongation } \\
(\%)\end{array}$ & Breaking work $(\mathrm{J})$ \\
\hline Untreated Cotton & $* * * * * * * * *$ & 85,3 & 3,94 & 9,727 & 8,794 & 0,235 \\
\hline YS1 & Modified Glyoxalic & 79,80 & 2,98 & 8,063 & 6,347 & 0,140 \\
\hline YS2 & Modified Glyoxalic & 75,99 & 6,56 & 7,269 & 5,535 & 0,105 \\
\hline YS3 & Modified Glyoxalic & 76,56 & 3,01 & 8,408 & 6,843 & 0,154 \\
\hline YS4 & Modified Glyoxalic & 79,67 & 5,39 & 7,071 & 6,001 & 0,108 \\
\hline YS5 & Modified Glyoxalic & 78,39 & 3,22 & 6,881 & 6,071 & 0,108 \\
\hline YS6 & Modified Glyoxalic & 84,88 & 3,08 & 7,630 & 6,049 & 0,123 \\
\hline TYA1 & Acrylic & 76,41 & 4,00 & 12,249 & 8,751 & 0,279 \\
\hline TYA2 & Acrylic & 69,92 & 3,27 & 12,252 & 7,283 & 0,241 \\
\hline TYA3 & Acrylic & 83,13 & 4,79 & 12,197 & 9,286 & 0,287 \\
\hline TYA4 & Acrylic & 81,95 & 3,93 & 12,360 & 8,949 & 0,286 \\
\hline TYA5 & Acrylic & 79,44 & 1,86 & 12,166 & 8,600 & 0,268 \\
\hline TYA6 & Acrylic & 80,77 & 1,59 & 11,688 & 8,452 & 0,256 \\
\hline
\end{tabular}

Table 5: The Crystallinity index, Crystallite size, and mechanicals properties of treated and untreated cotton yarns.

untreated cotton. However, acrylic crosslinkers improve the breaking strength of samples YSi (1-6) about 30\% and they have an unaffected breaking elongation compared to untreated cotton. This is probably due to the crosslinking of the acrylic agent that forms a coating film on a surface; thus, it reinforces the fiber. Firstly, this result confirms a significant change in crystallite size of the treated cotton. Secondly, we point out that crosslinkers agent contains a small amount of formaldehyde (modified glyoxalic DMDHEU has a formaldehyde $<0$, $1 \%)$ that affects negatively the mechanical properties of cotton yarns compared to acrylic crosslinkers agent (non-formaldehyde). Choi HM has mentioned that application of (non-formaldehyde) agents in crosslinking treatment with cotton may possibly recover the loss of the fabric strength Figure 5.

Figure 5 presents X-Ray diffraction of samples treated with modified glyoxalic crosslinkers and acrylic crosslinkers at various finishing conditions. A remarkable change was observed with intensity peaks for variation $2 \Theta=5-100^{\circ}$. It is clear that the modification of finishing conditions (dry temperature, dry time, and curing temperature, curing time and crosslinkers concentration) has an important effect on the microstructure of cotton, especially for the $\left(2 \Theta=18^{\circ}\right)$ and $\left(2 \Theta=22^{\circ}\right)$.

Referring to Figure 5, it is clear that the X-ray specters of different conditions applied YSi1-6 and TYAj1-6 have an intensity that results from special comparison to one to another. This change is certainly due to the reaction of crosslinkers agent's characteristics or to the finishing parameters (curing temperature and time, dry temperature and time). The results obtained in Figure 5 suggest that crystallinity and crystallite size (see Table 5). The constitution of cotton was customized with a head reaction with modified glyoxalic (DMDHEU). The diffusion of crosslinkers molecules added to the microstructure of cotton was showed with the L002 plan. Referring to, the appearance of small peaks near values of $\left(2 \Theta=78^{\circ}\right)$ and intensity of 100 especially for sample TYA1 is probably due to the finishing condition or catalyst reaction. We also construe from Figure 5 that the appearance of a full peak with a higher intensity of 800 near values of $\left(2 \Theta=78^{\circ}\right)$ for sample YS2 is probably owing to higher crosslinkers agent concentration used equal $150 \mathrm{~g}^{-1} \mathrm{l}^{-1}$ that is superior to applied concentration of other samples. A modest peak also appears with an intensity of 300 near values $\left(2 \Theta=38^{\circ}\right)$ for sample YS5 is probably due to a higher curing temperature of $140^{\circ} \mathrm{C}$ compared to other treated samples. This X-ray result led us to point out that effect of crosslinkers concentration and curing conditions is significant on the X-ray diffraction of various treated cotton yarns.

Referring to Table 5 presents the crystallinity CI and crystallite size
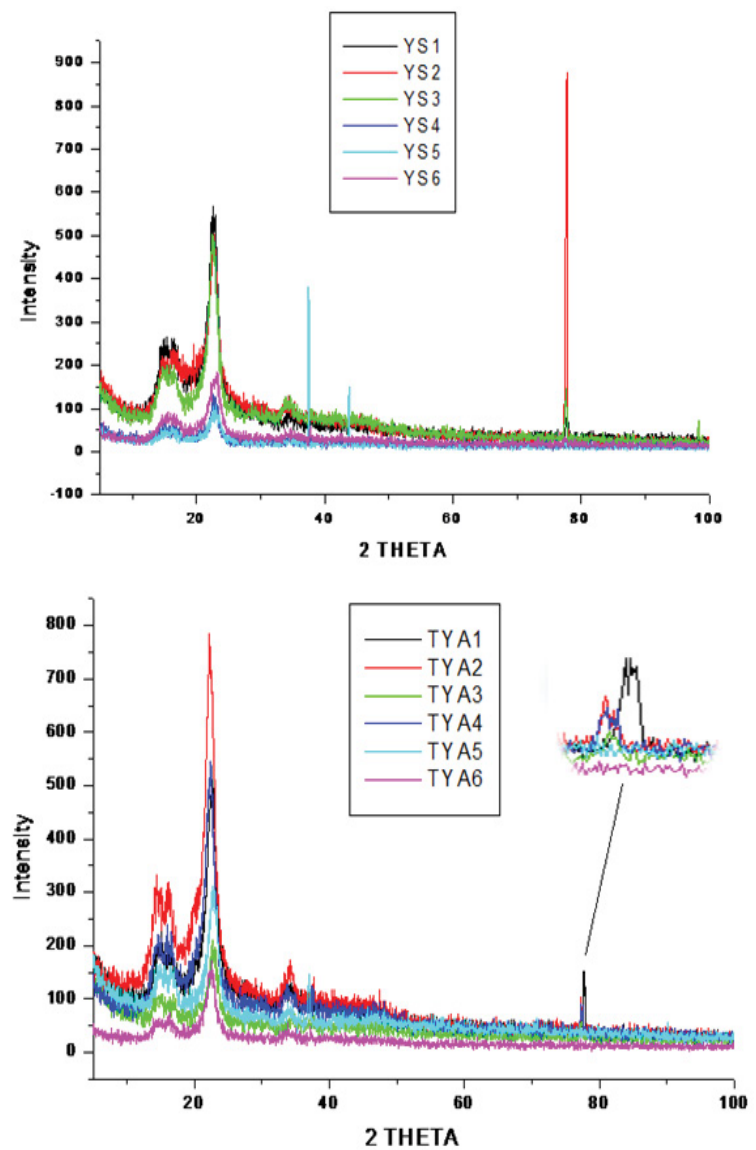

Figure 4: X-Ray diffraction of treated cotton yarns with modified glyoxalic DMDHEU and Acrylic crosslinkers at various finishing conditions.

of untreated and treated cotton with modified glyoxalic and acrylic crosslinkers. It is clear that the value of crystallinity index CI for all treated samples is less than CI of untreated cotton. We conclude that the crosslinking reaction affects crystallinity of cotton without the cross linker's type or the finishing condition. Nevertheless, the crystallite size changes values when the crosslinkers type is dissimilar; otherwise, the finishing condition changes. It is obvious that with modified glyoxalic crosslinkers, only the samples YS1 and YS3 have a crystallite size that is higher than crystallite size of untreated cotton. While for the samples 


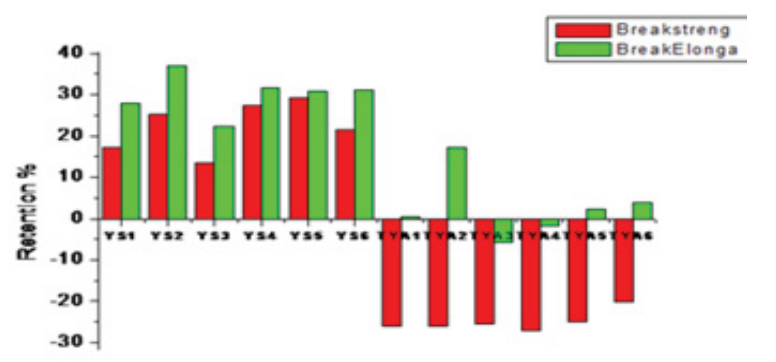

a)
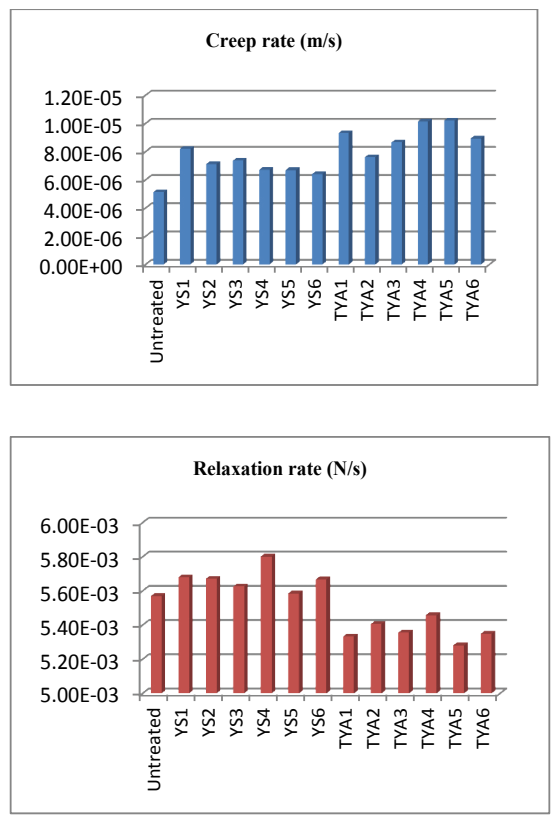

b)

Figure 5: a) Retention of breaking strength and elongation for treated cotton with modified glyoxalic DMDHEU and acrylic crosslinkers.

b) Creep and relaxation rate of untreated and treated cotton with modified glyoxalic DMDHEU and acrylic crosslinkers.

treated with acrylic crosslinkers, only the samples TYA 2 and TYA4 have a crystallite size higher than crystallite size of untreated cotton. Ericka $\mathrm{N}$ et al. suggest that the extension of DMDHEU breaks the hydrogen bond areas between the cellulose molecules. The crystallites size for a plane L002 increased throughout the DMDHEU inclusion; however, their growth was not directly related to the concentration DMDHEU. The increase in crystallinity of cellulose is associated with DMDHEU concentration. When intermolecular crosslinking starts, the competition between the groups $(\mathrm{OH})$ cellulose and glycol, high temperatures as well as affability of $(\mathrm{OH})$ groups of the cellulose are factors which could have influenced the non-linear extension of the crystalline size [27]. Xu Weilin observed a reduction in the crystallinity of the cross-linked cotton (BTCA: butane carboxylic acid). He mentions that it is possible that the properties are improved with each finishing agent cross-linked with cotton fiber to the state folded accompanied by different effects on the fine structure of cotton with various changes in the degree of crystallinity of the cellulose in the fiber. In addition, he reported that the crystallinity is closely related to the crystallite size of the fibers. After that, Parikh V. D. et al. observed the same notation: a reduction in crystallinity in the cotton cross-linked with DMDHEU and citric acid CA. It is known that the crystallinity and cotton crystallite size can be influenced by the maturity of the cotton fiber $[1,2,24]$. In this study, the treated and used yarns are from the same lot, while the maturity could be an important factor that indirectly influenced our experiments results. Researchers reported the results of X-rays that demonstrate a decrease in the typical crystallite size throughout drying step. Nevertheless, dehydration does not appear to affect the crystallinity significantly. They propose that in cotton dried crystals could have been stressed and dehydration. The deformation could happen in the inter-crystalline regions and inter-fibrils and could be nearly the surfaces of the crystals of the recently created intermolecular bond, which causes the reduction of the crystalline size without substantially affecting the crystallinity of the total dry fibers [26].

\section{Mechanical properties of treated cotton yarns}

Generally, studying the crosslinking effect on cotton fiber is necessary to the mechanical properties after finishing treatment. This reflex is required to perceive the crosslinkers effect on the mechanical behaviour of finished cotton fabric (Figures $5 a$ and $5 b$ ).

Figure 5 a presents the retention of breaking strength and elongation for treated cotton yarns with glyoxalic and acrylic crosslinkers. It is clear that breaking strength and breaking elongation have negative effects with glyoxalic than with acrylic crosslinkers, while acrylic crosslinkers reinforce fiber cotton and increase the breaking strength without changing the breaking elongation. This result is supported with pictures SEM addressed in the previous paragraph and confirms the reaction of acrylic crosslinkers, especially on fiber surface that is coated and more resistant. The samples YS3 have the minimum value of retention treated with Glyoxalic crosslinkers. This result clarifies that the dry temperature has not affected the mechanical properties of other finishing conditions. As for samples YS5 and YS6 (curing temperature and time) or YS2, they present the effect of higher crosslinks concentration $150\left(\right.$ g. $\left.\mathrm{l}^{-1}\right)$. Researchers clarify that resin treatments led to about $20 \%$ strength loss and treated fabrics have significant lower breaking strength. The decrease in tensile strength of cotton fabric treated with $\mathrm{N}$-methyl is a major result of the acid catalysts at elevated curing temperatures [13]. Choosing the proper acids as a catalyst is important because stronger acids are essential to catalyse the reaction of fewer reactive crosslinking reagents, except for the stronger the acid that causes damage to the cellulosic fibers through hydrolysis [20,28-30]. In our case, we have used MG catalyst for modified glyoxalic that is (magnesium chloride $\mathrm{MgCl}_{2}$ ) and $\mathrm{PAZ}$ for acrylic crosslinkers. The catalyst is $15 \%$ of crosslinkers weight. Other researchers confirmed that strength loss is the major inconvenience in wrinkle resistance of finished cotton fabrics due to acid-catalysed and crosslinking of cellulose [5,7]. Xu Weilin also declared that approximately $20 \%$ of strength loss resulted from the crosslinks. Such strength loss can be decreased by curing conditions that decrease the intermolecular crosslinks in the cotton fibers [12]. Shin Y et al., have pointed out that the high level of durable press properties, along with the retention of mechanical properties, in cotton fabrics treated by polymerization-crosslinking used with the wet fixation process are the consequence of two phenomena. One is the deconvolution of cotton fiber and the plasticity of interfaces between microstructures units of cellulose [31]. Researchers note two most important factors contributing to the loss in mechanical properties. They are the acid catalyst at elevated temperatures. For this reason, researchers have developed the wet fixation process in order to improve the retention 
Citation: Litim N (2019) Impact of Modified Glyoxalic and Co-polymer Acrylic Crosslinkers Effect on the Crystallinity and Mechanical Properties of Finished Cotton. J Textile Sci Eng 9: 391. doi: 10.4172/2165-8064.1000391

of mechanical properties in finished fabrics [32]. In previously studies, we have conducted experiments with the same used crosslinking agent. We ended the resin glyoxalic DMDHEU most affect the mechanical properties of cotton fabrics than copolymer acrylic resin; however, it was spraying technique applied $[33,34]$.

Figure $5 \mathrm{~b}$ presents the creep and relaxation rate of untreated and treated cotton with modified glyoxalic and acrylic crosslinkers. It is obvious that the creep rates of treated cotton with two different crosslinkers are higher than untreated cotton. In addition, the creep rates of samples TYAi treated cotton with acrylic crosslinkers are higher than the creep rate of samples treated with modified glyoxalic. Besides, the relaxation rates for samples treated with acrylic crosslinkers are less than the relaxation rate of untreated cotton. On the other hand, the relaxation rates for samples treated with modified glyoxalic are superior to relaxation rate of untreated cotton. Cotton fiber is wellknown for the cellulosic fiber and its polymer is related with a lot of hydroxyls $(\mathrm{OH})$ groups. The structural element of cellulose encloses crystalline region, amorphous region, and the middle region. In the crystalline region, the cellulose chains are intimately packed and, as a result, the mobility of the chains is little [14]. The obtained result of the creep and relaxation rates, for samples, YS $\mathrm{j}$ treated with modified glyoxalic that are in relation with values of breaking elongation are less than the breaking elongation of untreated cotton and breaking strength with acrylic crosslinkers that is superior to untreated cotton. This dissimilarity explains the effect of glyoxalic on the molecular chain of cellulose fiber compared to the action of acrylic crosslinkers.

\section{Conclusion}

The result obtained by using ATR FT-IR spectroscopy confirms the change on the physical sate of treated yarns with modified glyoxalic and acrylic crosslinkers, precisely with a functional group $\mathrm{OH}$ responsible for cross-linkage. X-ray diffraction analysis proves that crystallinity index and crystallite size determined of treated cotton with modified glyoxalic and acrylic crosslinkers have an important relation with physical properties such as accessibility to crosslinking in amorphous region and especially on mechanical properties. In addition, important modification of retention of breaking strength and elongation, creep and relaxation rate of treated cotton are investigated. We conclude that modified glyoxalic crosslinkers cause a decrease on crystallinity index maximum $15 \%$ with modified glyoxalic when compared to crystallinity index of untreated cotton. This decrease in crystallinity index is related to a decrease in breaking strength between $12 \%$ and $30 \%$ and reduction of breaking elongation between $18 \%$ and $36 \%$ compared to untreated cotton. As for acrylic crosslinkers, we have obtained a decrease in crystallinity index about $10 \%$ maximum when compared to crystallinity index of untreated cotton. However, acrylic crosslinkers improve the breaking strength of $30 \%$ and an unaffected breaking elongation compared to untreated cotton. This is due to cross-linkage of acrylic that formed a coating surface and reinforced the fiber. This result corresponds with a significant change in crystallite size after reaction of crosslinkers agents inside treated yarns.

\section{References}

1. Petersen H, Mark H, Wooding NS, Atlas SM (1971) Crosslinking chemicals and the chemical principles of the crosslinking finishing of cotton in chemical after treatment of textiles, Wiley-Inter-science, New York

2. Welch CM, Kottes ABA (1989) Ester crosslinks: a route to high performance non-formaldehyde finishing of cotton. Textile Chem Color 21: 13-17.

3. Wakelyn PJ, Bertoniere NR, French AD, Thibodeaux DP (2006) Cotton Fiber Chemistry \& Technology. Boca Raton, Taylor and Francis Group.
4. Petersen $H$ (1971) In situ formation of polymers "A crosslinking chemical and the chemical principles of resins finishing of cotton, chemical after treatment of textiles", $2^{\text {nd }}$. Edition (Mark H., Wooding N.S. and Atlas S.M.), WileyInterscience, New York, Pp: 135.

5. Tomasino C (1992) Chemistry \& technology of fabric preparation \& finishing North Carolina University.

6. Harifi T, Montazer M (2012) Past, present and future prospects of cotton crosslinking: New insight into Nano-particles. Carbohyd Polym 88: 1125-1140.

7. Sarko A, Young RA, Rowell RM (1986) In Cellulose Structure, Modification, and Hydrolysis. Edition John Wiley and Sons, New York.

8. Parikh DV, Thibodeaux DP, Condon B (2007) X-ray Crystallinity of Bleached and Cross-linked Cottons. Textile Res J 77-8.

9. Lal G, Pande A (1975) X-ray diffraction studies of native and mercerized cotton cellulose. Colourage 22: 21-27.

10. Aravindanath $S$, Bhama lyer $P$, Sreenivasan Layer S (1992) Layer Morphology and relation to swelling and structure, I. Cotton fiber treated in alkali metal hydroxides. J Appl Polym Science 46: 2239-2244.

11. Vigo TL, Welch CM (1971) Carbohydrate Res 17: 145-153.

12. Weilin X (2003) Effect of crosslinking treatment on the crystallinity, crystallite size, and strength of cotton fibers. Textile Res J 73: 433-436.

13. Yang CQ, Weishu W, Lickfield GC (2000) Mechanical Strength of durable Press finished cotton Fabric. Textile Res J, 70: 143-147.

14. Yang CQ (2002) FT-IR Spectroscopy Study of the Ester Crosslinking Mechanism of Cotton Cellulose. Textile Res J 61: 433-440.

15. Park S, Baker JO, Himmel ME, Parilla PA, Johnson D K (2010) Cellulose crystallinity index: Measurement techniques and their impact on interpreting cellulose performance. Biotechnol Biofuels 3: 10 .

16. Liu Y, Derveer DV, Gamble G, Thibodeaux D, Bauer P (2012) Comparative Investigation of Fourier Transform Infrared (FTIR) Spectroscopy and X-ray Diffraction (XRD) in the Determination of Cotton Fiber Crystallinity. Soc App Spect 66: 983-986.

17. Alexander LE (1969) X-Ray Diffraction Methods in Polymer Science. Wiley Inter-science, London.

18. Segal L, Creely Martin AE, Conrad CM (1959) An empirical method for estimating the degree of crystallinity of native cellulose using X-ray diffractometer. Textile Res J 29: 786-794.

19. Hindeleh AM (1980) Crystallinity, crystalline size and physical properties of native Egyptian cotton. Textile Res J 50: 667.

20. Cooke TF, Weigmann HD (1982) The chemistry of formaldehyde release from durable press fabrics. Textile Chem Color 14: 33-41.

21. Cooke T.F, Weigmann HD (1982) The chemistry of formaldehyde release from durable press fabrics. Textile Chem Color 14: 136-144.

22. Cheriaa R, Baffoun A (2015) Effects of Cross-Linkers Combination, for ThreeDimensional Effects, on Denim Garment Properties. Fibers and Polym 16: 1150-1155.

23. Fan Q (2005) Handbook chemical testing of textiles, Woodhead Publishing Ltd with The Textile Institute, pp. 90-100.

24. Orhan M (2013) Crease Resistant Effect of Modified DMDHEU and softeners on cotton woven fabric. Tek Ve konfek 23: 152-158.

25. Schindler WD, Hauser PJ (2004) Chemical finishing of textiles, By Woodhead Publishing Ltd, Pp: 51-73.

26. Hu XP, Hsieh YL (2001) Effects of Dehydration on the Crystalline Structure and Strength of Developing Cotton Fibers. Textile Res J 71: 231-239.

27. Choi HM (1992) Nonformaldehyde polymerization crosslinking treatment of cotton fabrics for improved strength retention. Textile Res J 62: 614-618.

28. Ford ENJ, Mendon SK, Thames SF, James W (2010) X-ray Diffraction of Cotton Treated with Neutralized Vegetable Oil-based Macromolecular Crosslinkers. J Eng Fiber Fabric 5: 12-16.

29. Brodmann GL (1990) Performance of Nonformaldehyde cellulose reactants Textile Chem Color 22: 13-16.

30. Abdel Mohdy FA, Aly AS, Hebeish A (2004) Antimicrobial and wrinkle resistance finishing for cotton using polycarboxylic acids. J Text Assoc 65: 25-30. 
Citation: Litim N (2019) Impact of Modified Glyoxalic and Co-polymer Acrylic Crosslinkers Effect on the Crystallinity and Mechanical Properties of Finished Cotton. J Textile Sci Eng 9: 391. doi: 10.4172/2165-8064.1000391

Page 8 of 8

31. Shin Y, Hollies NRS, Yeh K (1989) Polymerization crosslinking of cotton fabric for superior performance properties. Part I: a preliminary study. Textile Res $\mathrm{J}$ 59: $635-642$

32. Hollies NRS, Getchell NF (1967) Wet-fixation process for improved durablepress cotton1. Textile Res J 37: 70-76

33. Litim N, Baffoun A, Ben Abdessalem S (2016) Impact of modified DMDHEU and copolymer acrylic resin using spraying treatment before and after an enzymatic washing on the mechanical properties of denim cotton fabric. J Poly Text Eng 3: 24-34

34. Litim N, Baffoun A (201) Investigation of acrylic resin treatment and evaluation of cationic additive quality impact on the mechanical properties of finished cotton fabric. Inter J Eng Advanced Technol 5: 76-84. 